\title{
Letter from the President of Korean Knee Society
}

\section{Dear Korean Knee Society members,}

The Korean Knee Society has grown to be one of the largest societies in the Korean Orthopedic Association since the foundation of in 1983. It is our great pleasure to launch Knee Surgery and Related Research. The journal covers all fields of clinical orthopedic knee surgery and basic research related to orthopedic knee surgery. This journal is the product of long and patient planning by many whose hard work has led finally to its fruition. I would like to thank professors, Jeung-Tak Suh and Seong-Il Bin as well as the other journal planning committee members for charting the path for the journal.

We look forward to receiving your manuscript submissions and your advice about the English journal of Korean Knee Society. We will be successful with your enthusiastic supports and contributions.

President of Korean Knee Society

Nam-Yong Choi, MD

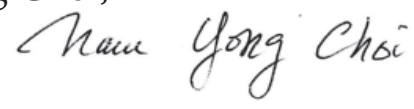

Correspondence to: Nam-Yong Choi, MD.

Departemnt of Othopedic Surgery, St. Paul's Hospital of Catholic University,

620-56 Jeunong-dong, Dongdaemun-gu, Seoul 130-709, Korea.

Tel: +82-2-958-2159, Fax: +82-2-965-1456

Email: nychoimay@yahoo.co.kr 